CLINICAL STUDY

\title{
Sleeping during the day: effects on the 24-h patterns of IGF-binding protein 1, insulin, glucose, cortisol, and growth hormone
}

\author{
Javaid-ur Rehman ${ }^{1}$, Kerstin Brismar ${ }^{2}$, Ulf Holmbäck ${ }^{3}$, Torbjörn Åkerstedt ${ }^{4}$ and John Axelsson ${ }^{1,5}$ \\ ${ }^{1}$ Section for Psychology, Department of Clinical Neuroscience, Karolinska Institutet, 17177 Stockholm, Sweden, ${ }^{2}$ Department of Molecular Medicine and \\ Surgery, Karolinska Institutet, 17176 Stockholm, Sweden, ${ }^{3}$ Department of Public Health and Caring Sciences, Clinical Nutrition and Metabolism, Uppsala \\ University, 75185 Uppsala, Sweden, ${ }^{4}$ Stress Research Institute, Stockholm University, 10691 Stockholm, Sweden and ${ }^{5}$ Osher Center for Integrative \\ Medicine, 17177 Stockholm, Sweden
}

(Correspondence should be addressed to J-u Rehman; Email: javaid.ur.rehman@ki.se)

\begin{abstract}
Background: Disturbed sleep is a major risk factor for metabolic disturbances, including type 2 diabetes, but the involved mechanisms are still poorly understood. We investigated how an acute shift of sleep to the daytime affected IGF-binding protein 1 (IGFBP1), which is a risk factor for diabetes.

Methods: Seven healthy men (age, 22-32 years) participated in a night sleep condition (sleep 2300-0700 h) and a day sleep condition (0700-1500 h) with hourly blood samples taken for $25 \mathrm{~h}$ (starting at $1900 \mathrm{~h}$ ) and isocaloric meals every 4th hour awake. The blood samples were analyzed for IGFBP1, insulin, GH, glucose, and cortisol.

Result: The acute shift of sleep and meal timing (to $8 \mathrm{~h}$ ) shifted the 24-h patterns of IGFBP1, glucose, insulin, and GH to a similar degree. However, the day sleep condition also resulted in elevated levels of IGFBP1 (area under curve (AUC) $+22 \%, P<0.05$ ), and reduced glucose levels (AUC $-7 \%, P<0.05$ ) compared with nocturnal sleep. Sleeping during the day resulted in elevated cortisol levels during early sleep and reduced levels in late sleep, but also in increased levels the subsequent evening $(P$ 's $<0.05)$. Conclusion: Sleep-fasting seems to be the primary cause for the elevation of IGFBP1, irrespective of sleep timing. However, sleeping during the day resulted in higher levels of IGFBP1 than nocturnal sleep, suggesting altered metabolism among healthy individuals, which may have implications for other groups with altered sleep/eating habits such as shift workers. Moreover, sleep and meal times should be accounted for while interpreting IGFBP1 samples.
\end{abstract}

European Journal of Endocrinology 163 383-390

\section{Introduction}

Disturbed sleep has rendered an increased awareness as a risk factor for obesity, type 2 diabetes mellitus (T2DM) (1), and cardiovascular diseases (2). Experimental studies have shown that sleep restriction and disturbances may cause glucose intolerance, insulin resistance, and enhancement of appetite (3); however, the mechanisms are still poorly understood.

A possible mechanism linking disturbed sleep to metabolic disturbances, which has not yet been investigated, may be insulin-like growth factor-binding proteins (IGFBPs), proteins in the circulation that bind IGFs (IGF1 and IGF2) and determine the bioavailability of these factors, as well as having direct effects themselves (4). IGFBP1 secretion in humans is mainly regulated at transcriptional level by insulin (5) and also by other counterregulatory hormones like glucocorticoids (6) and growth hormone (GH). Since sleep has regulatory effects on the above variables, it seems likely that sleep and disturbed sleep could have downstream effects on IGFBP1.

The characteristic 24-h rhythmicity of IGFBP1 has been accredited to the inverse association between insulin and IGFBP1 (7). The main characteristic of IGFBP1 is suppressed levels when meals are regular and an augmentation in response to fasting (8). A limitation is that previous studies have reported the patterns of IGFBP1 under normal nocturnal sleep paradigms only, and it is not known how the displacement of sleep to daytime, which occurs in connection with night work or other night activity, will affect IGFBP1 regulation.

The current study aimed to evaluate the impact of normal and acutely displaced sleep on IGFBP1 regulation by experimentally shifting sleep in a well-controlled setting with standardized meals. Thus, we investigated the 24-h pattern of IGFBP1 during two conditions, during normal sleep (2300-0700 h) and 
during an acute shift of sleep (0700-1500 h), a pattern common among shift workers. To investigate possible mechanisms behind the influence of sleep on IGFBP1, we also measured insulin, glucose, GH, and cortisol, all of which have been considered to take part in the regulation or dysregulation of IGFBP1. Since sleep is the longest period (normally) without regular food intake, another aim was to investigate whether the effects of sleep-fasting on IGFBP1 differed when sleep was acutely shifted to the daytime.

\section{Methods}

\section{Participants}

Seven healthy males (mean age 25 years, range 22-32 years) participated. They were nonsmokers, nonobese (body mass index (BMI) range, $21-25 \mathrm{~kg} / \mathrm{m}^{2}$ ) moderate alcohol consumers with a body fat composition of $16 \pm 4 \%$ and on no medications. Participants were recruited from two universities in the Stockholm area. The study was approved by local ethical committee at Karolinska Institutet. All participants gave written informed consent after the procedure had been fully explained.

\section{Study protocol}

Starting one week prior to coming to the sleep laboratory and throughout the study, the participants adhered to a sleep protocol with bedtime at $2300 \mathrm{~h} \pm 30 \mathrm{~min}$ and rise time at $0700 \mathrm{~h} \pm 30 \mathrm{~min}$. All participants came to the sleep laboratory on three occasions: habituation sleep $(2300-0700 \mathrm{~h})$, nocturnal sleep $(2300-0700 \mathrm{~h})$, and diurnal sleep (0700$1500 \mathrm{~h}$ ), with the latter two in a balanced order. After arriving at $1730 \mathrm{~h}$, they stayed until $2100 \mathrm{~h}$ the following evening. At $1800 \mathrm{~h}$, an i.v. catheter was introduced into a forearm vein for a slow infusion of $0.9 \% \mathrm{NaCl}$. Hourly blood samples $(10 \mathrm{ml})$ were drawn from an adjacent room for $24 \mathrm{~h}$ starting at $2100 \mathrm{~h}$. Subjects remained in supine position from 1930 to $2100 \mathrm{~h}$ the following evening. Polysomnography was recorded continuously during the same time. The light at bedside was 70 lux. Standardized meals (an isocaloric diet of 45 energy percent fat, 15\% proteins, and $40 \%$ carbohydrates) were given at 2200 and $1600 \mathrm{~h}$ during both conditions, at 0200 and $0600 \mathrm{~h}$ before diurnal sleep, and at 0800 and $1200 \mathrm{~h}$ after nocturnal sleep, in order to keep a stable 24-h energy balance. All subjects adhered to a $2100 \mathrm{kcal} /$ day schedule as all of them weighed around $70 \mathrm{~kg}$ (BMI range, $21-25 \mathrm{~kg} / \mathrm{m}^{2}$ ). The whole protocol (information of timing of blood samples, sleep timings, and food intake) under both conditions is also presented in the form of figures (Figs 1 and 2).
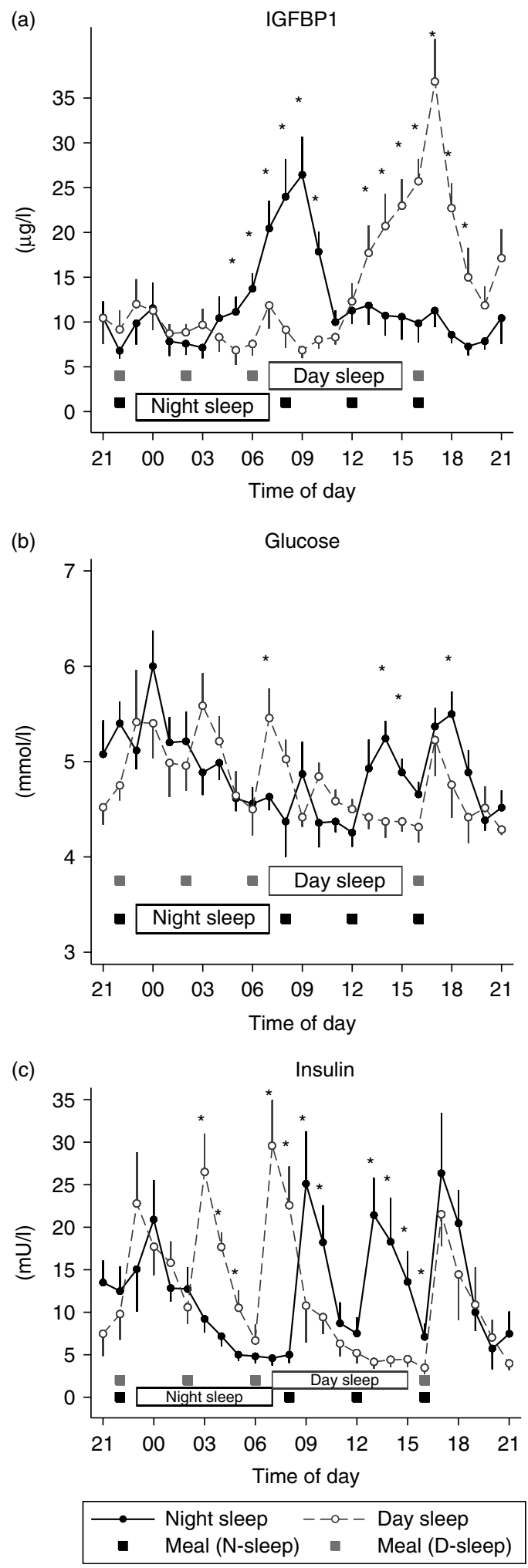

Figure 1 Mean and S.E.M. for circulating (a) IGFBP1, (b) glucose, and (c) insulin levels, across $24 \mathrm{~h}$ of the day, under the day and night sleep conditions. ${ }^{*} P<0.05$ (significant difference for the corresponding time point under the two conditions). 


\section{Sleep}

Electrodes were attached for the recording of two electroencephalograms (C3-A2 and C4-A1), two electroocculograms, and one electromyogram (submental). Sleep stages were scored in 30-s epochs, using standardized methods (9). The parameters used were time in bed (lights off to awakening), sleep latency (lights off to first stage 2 sleep), wake time after sleep onset, total sleep time (real sleep time), sleep efficiency, rapid eye movement (REM) latency (time to first REM), and sleep stages 1, 2, 3, and 4 (stages 3 and 4 are shown as slow wave sleep (SWS)) and REM. None of the sleep parameters except sleep latency (night sleep $=22 \pm 6$ versus day sleep $=5 \pm 1$ ) differed significantly between conditions, with total sleep time (night sleep $=401 \pm 15$ versus day sleep $422 \pm 5$ ) and sleep efficiency (\%) (night sleep $=92 \pm 1$ versus day sleep $89 \pm 1)(10)$.

\section{Biochemical assays}

Serum samples were centrifuged, separated, frozen at $-20{ }^{\circ} \mathrm{C}$, and stored at $-73^{\circ} \mathrm{C}$ directly after each day until analysis. Serum IGFBP1 concentrations were determined by RIA according to the method of Povoa (11). The sensitivity of RIA was $3 \mu \mathrm{g} / \mathrm{l}$, and the intraand inter-assay coefficients of variation (CV) were 3 and $10 \%$ respectively. Serum cortisol was determined by AutoDELFIA (B060-101) automatic immunoassay kit (manufactured by Wallac Oy, Turku, Finland), which has a sensitivity of $15 \mathrm{nmol} / \mathrm{l}(0.54 \mu \mathrm{g} / \mathrm{dl})$ with intraand inter-assay $\mathrm{CV}$ of 3.5 and $1.6 \%$. Serum GH was determined by AutoDELFIA (B041-101) fluoroimmunoassay kit (manufactured by Wallac Oy), having a sensitivity of $0.03 \mathrm{mU} / \mathrm{l}$ with intra- and inter-assay $\mathrm{CV}$ of 5.1 and $2.5 \%$. Plasma glucose was analyzed at the Clinical Chemistry routine laboratory at the Uppsala University Hospital, Sweden. Insulin was measured with an automated system for immunological analyses (Auto-Delfia, Wallac Oy).

\section{Statistical analyses}

The dependent measures were analyzed with mixed effects repeated measures ANOVA techniques. In order to compare the general changes due to the acute shift of sleep (e.g. sleep versus wakefulness during the night) and across the sleep-fasting (night sleep versus day sleep), the dataset was analyzed twice, first by 24-h period and secondly with respect to sleep-fasting. The ANOVAs included condition (normal night sleep versus day sleep) and time ( $25 \mathrm{~h}$ synchronized with respect to clock time) when analyzed for the 24-h duration, whereas condition and sleep-fasting (time synchronized with respect to the presleep meal to $4 \mathrm{~h}$ after the postsleep meal) when the data were analyzed for the sleep-fasting comparisons. The latter analyses included $4 \mathrm{~h}$ after the postsleep meal since we intended to study (a)

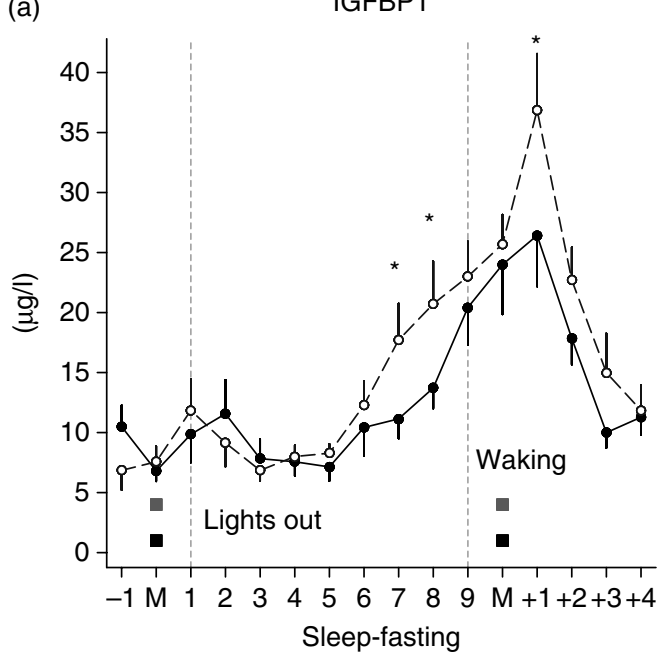

(b)
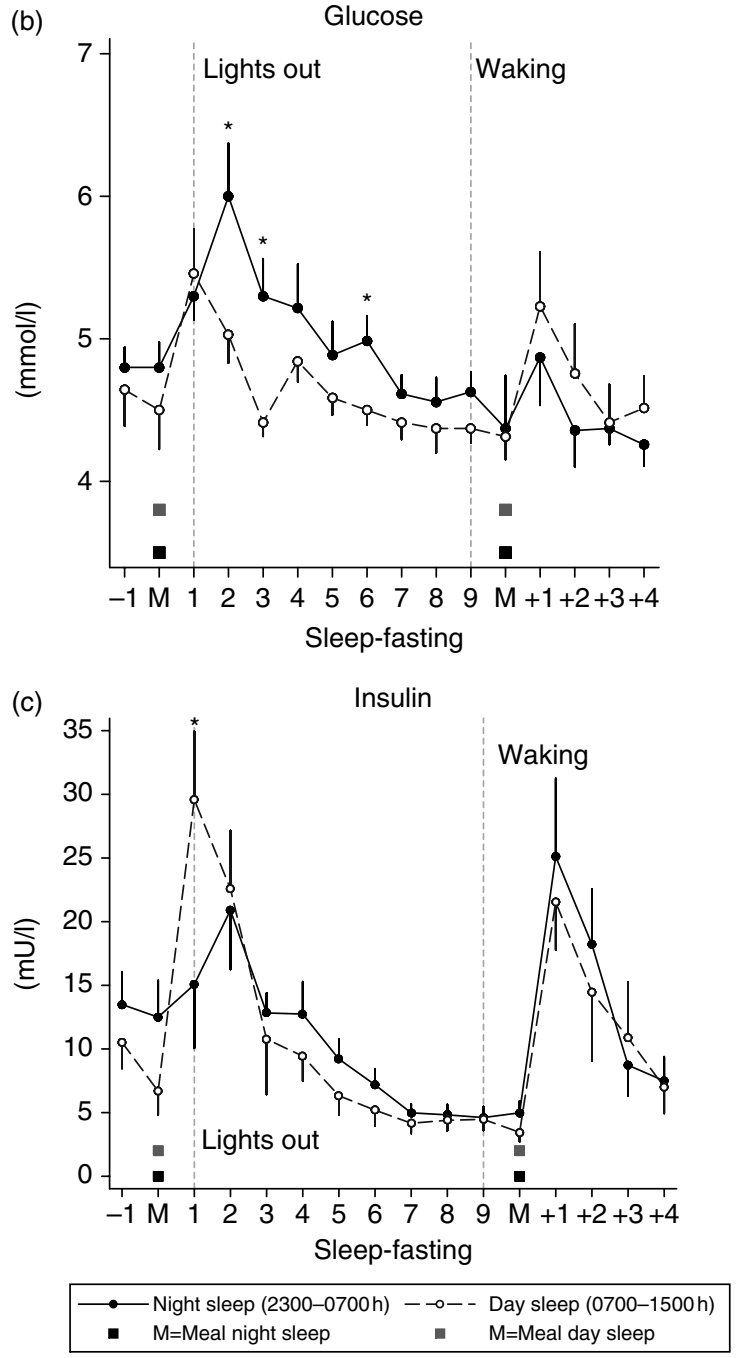

Figure 2 Mean and S.E.M. for circulating (a) IGFBP1, (b) glucose, and (c) insulin levels, across the sleep-fasting and postawakening period, under the day and night sleep conditions. ${ }^{*} P<0.05$ (significant difference for the corresponding time point under the two conditions). 
the downstream effects of sleep-fasting - effects that have not yet receded at the end of sleep and may possibly continue up to several hours after the postsleep meal. The analyses also allowed individuals to have random intercepts. Huyhn-Feldt epsilon correction was applied in order to adjust for violations against the assumption of sphericity. Planned $t$-tests were made between corresponding time points under the two conditions, and AUC analyses were done for IGFBP1, glucose, and insulin during sleep-fasting and even after the postawakening meal. In order to evaluate the downstream effects of sleep and sleep-fasting on IGFBP1 level, AUC analysis was done from presleep meal to $4 \mathrm{~h}$ after postawakening meal. Regarding both glucose and insulin, which are highly meal sensitive, AUC analysis was done in two portions, i.e. sleep-fasting analysis ranging from presleep meal to postsleep meal and postawakening meal analysis ranging from postawakening meal to $3 \mathrm{~h}$ afterwards (the time point before the second postsleep meal). The statistical analyses were made with STATA (9.2, Statacorp, TX, USA), and 0.05 was set as the significance level.

\section{Results}

\section{IGFBP1}

There was no significant main effect of condition on 24-h levels of IGFBP1 levels, either analyzed by all data points (Table 1 and Fig. 1a), or by 24-h area under curve (AUC), AUC day sleep condition=323 \pm 37 (mean AUC \pm s.E.M.) and night sleep condition $=285$ $\pm 32(P>0.05)$. However, there were significant main effects of time of the day and the interaction between time of the day and condition. (Fig. 1a and Table 1). T-tests between corresponding time points revealed significantly elevated IGFBP1 levels from 0500 to $1000 \mathrm{~h}$ during the night sleep condition and from 1300 to $1900 \mathrm{~h}$ during the day sleep condition, compared with the other respective condition (Fig. 1a).

With respect to sleep-fasting-related changes (time synchronized with respect to the presleep meal to $4 \mathrm{~h}$ after the postsleep meal), IGFBP1 varied strongly across time, but there was no significant main effect for condition or interaction between time and condition
(Fig. 2a and Table 1). Under both conditions, IGFBP1 began to rise $4 \mathrm{~h}$ after bedtime ( $5 \mathrm{~h}$ after the last meal) and increased until $2 \mathrm{~h}$ after awakening, thereafter IGFBP1 declined sharply, reaching close to baseline levels almost $2 \mathrm{~h}$ later (Fig. 2a). This pattern was consistent across individuals, and all displayed their highest levels $2 \mathrm{~h}$ after awakening ( $1 \mathrm{~h}$ after the first postsleep meal). The $t$-tests showed that IGFBP1 levels for the daytime sleep were significantly augmented in the last part of sleep (at 6 and $7 \mathrm{~h}$ after bedtime) and $2 \mathrm{~h}$ after awakening, compared with night sleep ( $P$ 's $<0.05$, Fig. 2a). The AUC peak of IGFBP1 was $22 \%$ higher during day sleep-fasting compared with night sleepfasting $(228 \pm 29$ vs $187 \pm 23, P<0.05$; Fig. 2a).

\section{Glucose}

With respect to 24-h levels of glucose, there was no significant main effect of condition, but significant effects were observed for the time of day and interaction between time and condition (Fig. $1 \mathrm{~b}$ and Table 1). The changes of the 24-h glucose pattern were largely associated with the different timing of food between conditions. The levels of glucose were stable across sleep in both conditions, but lower during daytime sleep; AUC (limited to the levels between the pre- and postsleep meals) was $7 \%$ lower during day sleep, compared with the night sleep ( $46 \pm 1$ vs $50 \pm 2 ; P<0.05$; Fig. 2b). $T$-tests showed that glucose was significantly reduced at 1,2 , and $5 \mathrm{~h}$ after bedtime during day sleep $(P$ 's $<0.05)$. The glucose response after the first postsleep meal did not differ significantly between conditions (AUC day sleep condition $=15 \pm 1$ versus night sleep condition $=14 \pm 1, P>0.05$; Fig. 2b).

\section{Insulin}

Both analysis by time of the day and by sleep-fasting, did not result in significant main effects of condition, but there were strong effects of the time, as well as interactions between condition and time $(P<0.05$; Table 1). The time effects on insulin levels were related to food intake, and the interactions were related to the different timing of food intake under the two conditions (Fig. 1c). The $t$-test analysis between corresponding

Table $1 F$-values and $P$ levels for the ANOVA for insulin-like growth factor-binding protein 1 (IGFBP1), glucose, insulin, cortisol, and GH analyzed by $24 \mathrm{~h}$ and by sleep-fasting (from presleep meal to $4 \mathrm{~h}$ after first postsleep meal).

\begin{tabular}{|c|c|c|c|c|c|c|}
\hline & \multicolumn{3}{|c|}{ 24-h period } & \multicolumn{3}{|c|}{ Sleep fasting } \\
\hline & Condition & Time & $\mathrm{C} \times \mathrm{T}$ & Condition & Time & $\mathrm{C} \times \mathrm{T}$ \\
\hline IGFBP1 & 0.77 & $6.89^{\ddagger}$ & $16.40^{\ddagger}$ & 2.64 & $39.60^{\ddagger}$ & 1.13 \\
\hline Glucose & 0.64 & $4.57^{\ddagger}$ & $2.54^{\dagger}$ & 4.00 & $7.21^{\ddagger}$ & 1.72 \\
\hline Insulin & 0.42 & $12.46^{\ddagger}$ & $10.54^{\ddagger}$ & 3.54 & $24.79^{\ddagger}$ & $2.66^{*}$ \\
\hline Cortisol & 2.23 & $25.98^{\ddagger}$ & $2.87^{\dagger}$ & $19.71^{*}$ & $10.57^{\ddagger}$ & $17.97^{\ddagger}$ \\
\hline $\mathrm{GH}$ & 1.73 & 1.44 & $3.29^{\ddagger}$ & 0.59 & $5.20^{\dagger}$ & $2.54^{*}$ \\
\hline
\end{tabular}

C, condition; T, time. Significance levels are ${ }^{*} P<0.05,{ }^{\dagger} P<0.001,{ }^{\ddagger} P<0.0001$. 
time points found no significant difference, except at bedtime, when insulin was significantly elevated for the day sleep condition (Fig. 2c). The AUC across sleep, calculated between the pre- and postsleep meals, was similar between conditions $(104 \pm 14$ vs $105 \pm 16$, for the day and night sleep conditions respectively, $P>0.05$; Fig. 2c). The insulin response after the first meal after sleep did not differ significantly between conditions (AUC day sleep condition $=46 \pm 15$, night sleep condition $=54 \pm 16 ; P>0.05$; Fig. $2 \mathrm{c}$ ).

\section{Cortisol}

For 24-h levels of cortisol, there was no significant main effect between conditions, but time of day and its interaction with condition showed significant effects (Table 1). The main 24-h profile was similar under both conditions; however, the levels were elevated from 0200 to $0300 \mathrm{~h}$ for day sleep condition (when subjects were awake), and from 0800 to $0900 \mathrm{~h}$ for night sleep condition (when subjects were sleeping for day sleep condition; P's $<0.05$ (Fig. 3a). Moreover, the evening cortisol levels were also significantly augmented for day sleep condition from 1600 to $2000 \mathrm{~h}(P$ 's < 0.05). T-test analysis showed that the nocturnal rise of cortisol began earlier $(\sim 1-\mathrm{h})$ in the day sleep condition, when subjects lay awake in bed. The individual peaks ranged between 0600 and $0900 \mathrm{~h}$ irrespective of condition. The analysis of sleep-fasting (including the sleep and its downstream effects in the postawakening period) showed significant main effects for condition, time of day, and the interaction between the two (Table 1). During the day sleep, cortisol levels were elevated in the first part of sleep and lower in the last part of sleep and after awakening compared with the night sleep (Fig. 4a).

\section{GH}

With respect to 24-h period, there were no significant main effects for time and condition, but the significant interaction showed that the biggest GH peak occurred $(\sim 8 \mathrm{~h})$ later when sleep was postponed with $8 \mathrm{~h}$ in the day sleep condition (Table 1 and Fig. $3 b$ ). The analysis with respect to sleep-fasting showed significant effects of time and the interaction; however, the effects of condition were nonsignificant (Table 1). Although the patterns were similar, $t$-tests showed that $\mathrm{GH}$ levels were elevated during the day sleep at 4,6 , and $7 \mathrm{~h}$ after lights out (LO; Fig. 4b).

\section{Discussion}

The present study showed that the fasting properties of sleep on IGFBP1 are largely maintained when sleep and meal timing is acutely shifted by $8 \mathrm{~h}$. This includes stable levels of IGFBP1 during waking hours (when meal timing is regular) followed by a significant
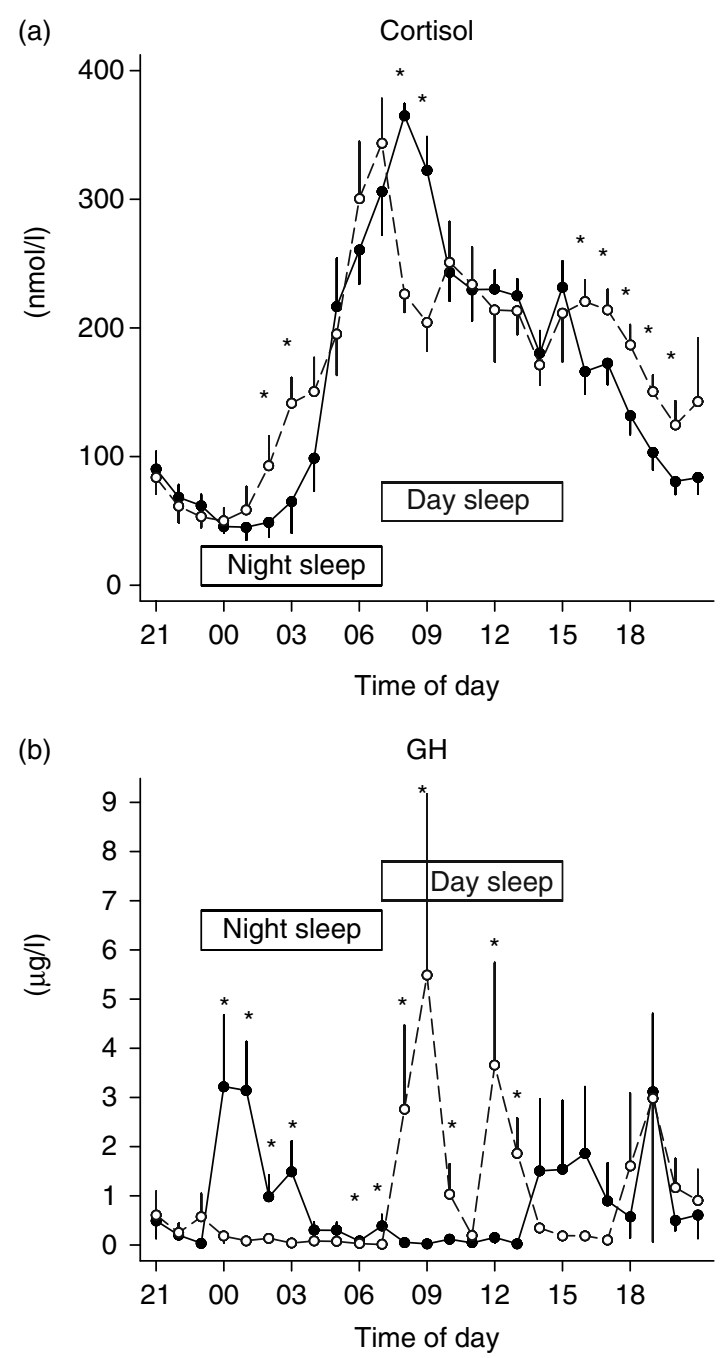

—_ Night sleep - - o- - Day sleep

Figure 3 Mean and S.E.M. for circulating (a) cortisol and (b) GH, across $24 \mathrm{~h}$ of the day, under the day and night sleep conditions. ${ }^{*} P<0.05$ (significant difference for the corresponding time point under the two conditions).

elevation of IGFBP1 in the last part of sleep and the first hour after awakening, with levels decreasing sharply $1 \mathrm{~h}$ after breakfast. Although this pattern was similar in both conditions, the sleep-fasting-induced increase in IGFBP1 was more pronounced when sleep was acutely shifted to the day. The data support a close relationship between meal timing, insulin, and IGFBP1 $(7,8)$, and that sleep-fasting is the main predictor of the 24-h variation of IGFBP1. However, it also shows that an acute shift of sleep results in altered or disturbed metabolic regulation of IGFBP1. The altered regulation of IGFBP1 should be seen in the light of disturbed sleep and shift workers, which are subjected to the shifted sleep and have elevated risk for developing T2DM, cardiovascular disorders, and metabolic 
(a)

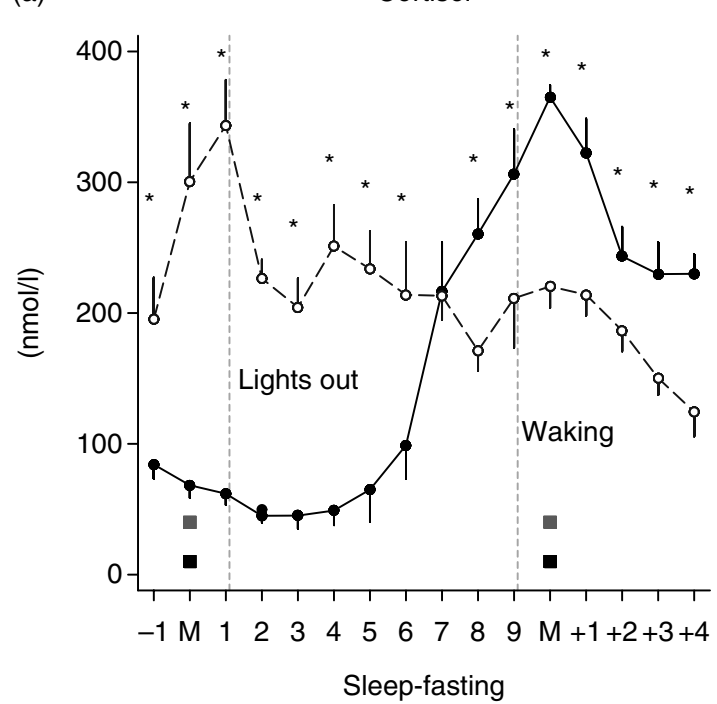

(b)

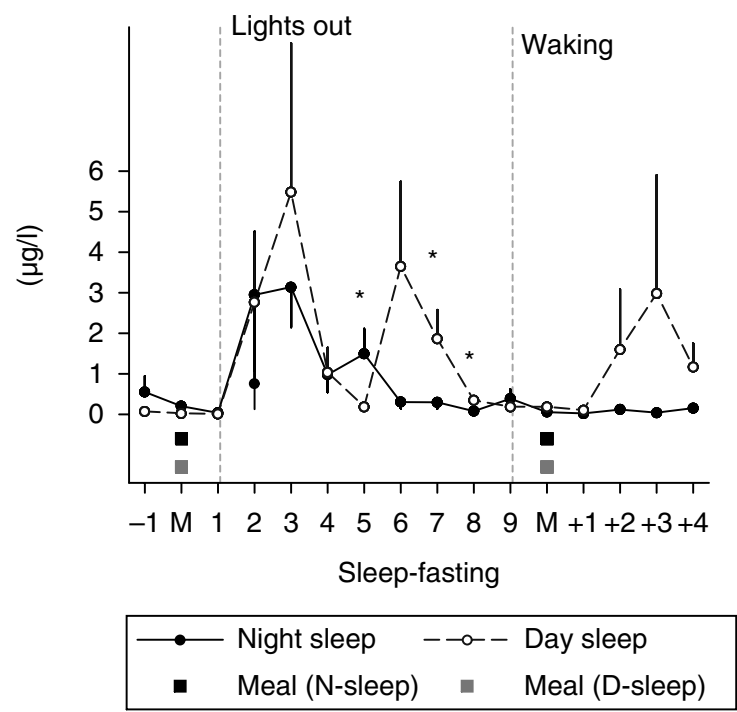

Figure 4 Mean and S.E.M. for circulating (a) cortisol and (b) GH, across the sleep-fasting and postawakening period, under the day and night sleep conditions. ${ }^{*} P<0.05$ (significant difference for the corresponding time point under the two conditions).

disorders $(1,12,13)$; disorders characterized by altered IGFBP1 regulation as a predictor $(14,15)$.

The exact mechanism behind the augmented levels of IGFBP1 levels during the latter part of day sleep and the hours after awakening is unclear. A possible mechanism may be impaired insulin sensitivity (16). In the present study, this could have been caused by several factors including sleeping at another circadian phase or by extended the time spent awake; participants were awake for another $8 \mathrm{~h}$ in the day sleep condition. Another characteristic difference of sleeping during the day is that the sleep now occurs at another phase of the cortisol curve. The fact that both IGFBP1 and cortisol normally peak during the last part of sleep has previously led to the suggestion that cortisol plays a role in increasing the levels of IGFBP1 $(6,16)$. Our data support the opposite relationship as the shift of sleep to the day resulted in increased IGFBP1 levels at a time when cortisol was considerably low, as compared with that of night sleep. Thus, it seems that the rise of IGFBP1 during last part of sleep cannot be attributed to the increase in cortisol. An inhibitory effect of exogenous corticosteroids on IGFBP1 has already been reported (17), besides the suppressed levels of IGFBP1 found in Cushing's disease, a disorder characterized by abnormally higher levels of cortisol (18). These studies suggest that cortisol normally has suppressive effects on IGFBP1, which may also explain the higher levels of IGFBP1 in the last part of day sleep; however, definitive conclusion cannot be drawn regarding the effects of cortisol on IGFBP1, as the current study did not analyze the relations between different hormones. We therefore propose that the increase in IGFBP1 at the end of the day sleep and after awakening is perhaps a result of both low insulin levels (due to fasting) and lower cortisol levels (due to sleeping at another phase of the cortisol rhythm), a proposition which needs elucidation. Further studies regarding the relation between IGFBP1 and cortisol during chronic sleep disturbances are needed in order to elaborate the long-term relation between cortisol and IGFBP1.

Serum IGFBP1 has been found to be elevated in untreated GH-deficient adults with normal to high insulin levels (19) and suppressed in acromegaly (a disorder with abnormally high levels of GH) (20), reflecting the possible role of $\mathrm{GH}$ in the regulation of IGFBP1. In the present study, the release of GH, in the first part of sleep occurred at a phase of sleep characterized by low levels of IGFBP1, supporting the view that GH directly or indirectly (via insulin dependent mechanisms) may inhibit IGFBP1 (21).

It is well established that insulin has a potent suppressive effect on IGFBP1 (5). The low and stable levels of IGFBP 1 during the first $3 \mathrm{~h}$ of sleep in the present study occurred at the same phase of sleep, which is characterized by elevated insulin. The gradual reduction in insulin, starting $4 \mathrm{~h}$ after sleep was followed by a simultaneous, but steeper rise of IGFBP1 starting after $4 \mathrm{~h}$ of sleep. IGFBP1 levels continued to rise until $1 \mathrm{~h}$ after breakfast under both conditions, and were thereafter reduced rather abruptly. This postprandial excursion of IGFBP1 is in accordance with earlier studies (8), and the subsequent drop is likely attributed to the insulin action with a time lag of more than $1 \mathrm{~h}$, and to the insulin-induced rapid clearance of IGFBP1, having a half life of 60-120 min (5). Moreover, in accordance with previous studies, the insulin-induced decline in abnormally high level of IGFBP1 in T1DM (22) and the failure of induced hyperglycemia to increase IGFBP1 during a constant degree of insulinization suggest that IGFBP1 is basically 
regulated by insulin, and that glucose per se does not affect the IGFBP1 (23). Thus, the steep rise of IGFBP1 during latter part of sleep is probably caused by low insulin levels. Further studies with manipulating sleep in combination with glucose/insulin infusions may shed light on the causality of the observed effects.

Despite the significant differences at a few corresponding time points, the 24-h rhythm of cortisol was quite stable under both conditions. The main differences were most likely due to the suppressing effects of initial sleep and an augmentation upon awakening, resembling the earlier findings of Weibel et al. (24). The elevation of cortisol during day sleep is in accordance with the studies of night workers, a group which exhibits elevated levels of cortisol during usual day sleep, in spite of their adapted sleep configuration (25). Moreover, the increase of cortisol in the evening during day sleep condition mimics the findings from studies of restricted sleep (26), insomnia (27), and depression (28). However, the reason for this cortisol increase remains unknown and needs further research.

The small number of participants (i.e. seven) and the use of a highly selected group of healthy adult males are the main limitations of the study. Thus, one needs to be careful in generalizing the results to other groups. In addition, the relatively infrequent (hourly) blood sampling precluded the detailed analysis of the postprandial rise and fall of insulin and glucose. For the same reason, a detailed analysis of $\mathrm{GH}$ peaks was not possible. The purpose was to investigate the effects of acutely shifted sleep and related sleep-fasting. A result of this was that time awake before sleep was different in the two conditions, i.e. $16 \mathrm{~h}$ in the night sleep conditions and $24 \mathrm{~h}$ in the day sleep condition. Thus, it was possible that the extra time awake could have influenced the results. Notably, this pattern of longer waking times is not artificially long, but resembles those that shift workers or night workers experience in relation to their first night shift. Although glucose, $\mathrm{GH}$, insulin, and cortisol were measured concomitantly with IGFBP1 under the two conditions, further studies should be directed to determine their exact correlations with IGFBP1 in order to address the causality issues, as well as the topic should be studied in future using other paradigms and preferably include other groups such as night workers and patients with sleep disorders.

Basal serum IGFBP1 is one of the potential candidate markers which can be used to differentiate between low insulin responders and high insulin responders (29); and to differentiate between T1DM and T2DM (30). Our data show that IGFBP1 levels in relation to day sleep are significantly lower in the morning (from 0500 to $1000 \mathrm{~h}$ ) than after night sleep (Fig. 1a), since subjects consumed food throughout the night. The strong elevation of IGFBP1 about 5-6 h after the last meal also suggests that both evening and night meals may have very strong impact on morning blood samples of IGFBP1. Thus, it is suggested that bed times and late evening/night eating habits are of high relevance for morning levels of IGFBP1, and should be accounted for in clinical and research settings.

In conclusion, sleep-fasting seems to be the primary cause for the elevation of IGFBP1, irrespective of sleep timing. However, sleeping during day resulted in higher levels than nocturnal sleep, suggesting altered metabolism among healthy individuals, which may have implications for other groups with altered sleep/eating habits, e.g. shift workers. The study also suggests that sleep and meal time should be accounted for while interpreting IGFBP1 samples, in both research and clinical settings.

\section{Declaration of interest}

The authors declare that there is no conflict of interest that could be perceived as prejudicing the impartiality of the research reported.

\section{Funding}

The work was supported by the Swedish Tercentenary fund; the Swedish council for working life and social research; the Swedish Medical Research Council (04224, K Brismar); and Family ErlingPersson Foundation.

\section{Acknowledgements}

The authors also thank Dr Anders Forslund for helping with the design of the study, R N Mirjam Ekstedt for help with the protocol, and Jeanette Forslund for meal calculations.

\section{References}

1 Akerstedt T \& Nilsson PM. Sleep as restitution: an introduction. Journal of Internal Medicine 2003254 6-12. (doi:10.1046/j.13652796.2003.01195.x)

2 Eguchi K, Pickering TG, Schwartz JE, Hoshide S, Ishikawa J, Ishikawa S, Shimada K \& Kario K. Short sleep duration as an independent predictor of cardiovascular events in Japanese patients with hypertension. Archives of Internal Medicine 2008 168 2225-2231. (doi:10.1001/archinte.168.20.2225)

3 Van Cauter E, Holmback U, Knutson K, Leproult R, Miller A, Nedeltcheva A, Pannain S, Penev P, Tasali E \& Spiegel K. Impact of sleep and sleep loss on neuroendocrine and metabolic function. Hormone Research 200767 (Supplement 1) 2-9. (doi:10.1159/ 000097543)

4 Holly J \& Perks C. The role of insulin-like growth factor binding proteins. Neuroendocrinology 200683 154-160. (doi:10.1159/ 000095523)

5 Brismar K, Hilding A \& Lindgren B. Regulation of IGFBP-1 in humans. Progress in Growth Factor Research 19956 449-456. (doi:10.1016/0955-2235(96)00006-3)

6 Conover CA, Divertie GD \& Lee PD. Cortisol increases plasma insulin-like growth factor binding protein-1 in humans. Acta Endocrinologica 1993128 140-143. (doi:10.1530/acta.0. 1280140)

7 Lewitt MS, Hall K, Bang P \& Brismar K. Altered response of insulin-like growth factor-binding protein 1 to nutritional deprivation in type 2 diabetes mellitus. Metabolism $2005 \mathbf{5 4}$ 275-280. (doi:10.1016/j.metabol.2004.09.005) 
8 Busby WH, Snyder DK \& Clemmons DR. Radioimmunoassay of a 26,000-dalton plasma insulin-like growth factor-binding protein: control by nutritional variables. Journal of Clinical Endocrinology and Metabolism 198867 1225-1230. (doi:10.1210/jcem-67-61225)

9 Rechtschaffen A \& Kales A. A Manual of Standardized Terminology, Techniques and Scoring System for Sleep Stages of Human Subjects. Bethesda: US Department of Health, Education and Welfare, Public Health Service, 1968.

10 Axelsson J, Ingre M, Akerstedt T \& Holmback U. Effects of acutely displaced sleep on testosterone. Journal of Clinical Endocrinology and Metabolism 200590 4530-4535. (doi:10.1210/jc.2005-0520)

11 Póvoa G, Roovete A \& Hall K. Cross-reaction of serum somatomedin-binding protein in a radioimmunoassay developed for somatomedin-binding protein isolated from human amniotic fluid. Acta Endocrinologica 1984107 563-570. (doi:10.1530/ acta.0.1070563)

12 Kawachi I, Colditz GA, Stampfer MJ, Willett WC, Manson JE, Speizer FE \& Hennekens CH. Prospective study of shift work and risk of coronary heart disease in women. Circulation 199592 3178-3182.

13 Koller M, Kundi M \& Cervinka R. Field studies of shift work at an Austrian oil refinery. I. Health and psychosocial wellbeing of workers who drop out of shiftwork. Ergonomics 197821 835-847. (doi:10.1080/00140137808931787)

14 Lewitt MS, Hilding A, Ostenson CG, Efendic S, Brismar K \& Hall K. Insulin-like growth factor-binding protein-1 in the prediction and development of type 2 diabetes in middle-aged Swedish men. Diabetologia 200851 1135-1145. (doi:10.1007/s00125-0081016-x)

15 Heald AH, Anderson SG, Ivison F, Laing I, Gibson JM \& Cruickshank K. C-reactive protein and the insulin-like growth factor (IGF)-system in relation to risk of cardiovascular disease in different ethnic groups. Atherosclerosis 2003 170 79-86. (doi:10. 1016/S0021-9150(03)00235-1)

16 Katz LE, Satin-Smith MS, Collett-Solberg P, Baker L, Stanley CA \& Cohen P. Dual regulation of insulin-like growth factor binding protein-1 levels by insulin and cortisol during fasting. Journal of Clinical Endocrinology and Metabolism $1998 \quad 83$ 4426-4430. (doi:10.1210/jc.83.12.4426)

17 Brismar K, Grill V, Efendic S \& Hall K. The insulin-like growth factor binding protein-1 in low and high insulin responders before and during dexamethasone treatment. Metabolism 199140 728-732. (doi:10.1016/0026-0495(91)90092-B)

18 Degerblad M, Povoa G, Thoren M, Wivall IL \& Hall K. Lack of diurnal rhythm of low molecular weight insulin-like growth factor binding protein in patients with Cushing's disease. Acta Endocrinologica 1989120 195-200. (doi:10.1530/acta.O. 1200195)

19 Hilding A, Brismar K, Degerblad M, Thoren M \& Hall K. Altered relation between circulating levels of insulin-like growth factor-binding protein-1 and insulin in growth hormone-deficient patients and insulin-dependent diabetic patients compared to that in healthy subjects. Journal of Clinical Endocrinology and Metabolism $1995 \mathbf{8 0}$ 2646-2652. (doi:10. 1210/jc.80.9.2646)
20 Hall K, Lundin G \& Povoa G. Serum levels of the low molecular weight form of insulin-like growth factor binding protein in healthy subjects and patients with growth hormone deficiency, acromegaly and anorexia nervosa. Acta Endocrinologica 1988118 321-326. (doi:10.1530/acta.0.1180321)

21 Norrelund H, Fisker S, Vahl N, Borglum J, Richelsen B, Christiansen JS \& Jorgensen JO. Evidence supporting a direct suppressive effect of growth hormone on serum IGFBP-1 levels. Experimental studies in normal, obese and GH-deficient adults. Growth Hormone and IGF Research 19999 52-60. (doi:10.1054/ ghir.1998.0087)

22 Brismar K, Gutniak M, Povoa G, Werner S \& Hall K. Insulin regulates the $35 \mathrm{kDa}$ IGF binding protein in patients with diabetes mellitus. Journal of Endocrinological Investigation $198811599-602$.

23 Fowelin J, Attvall S, von Schenck H, Smith U, Lager I \& Hall K. Regulation of insulin-like growth factor binding protein-1 (IGFBP-1) in insulin-dependent diabetes mellitus. Effects of hyperglycaemia and insulin. Acta Diabetologica 199431 183-186. (doi:10.1007/BF00571948)

24 Weibel L, Follenius M, Spiegel K, Ehrhart J \& Brandenberger G. Comparative effect of night and daytime sleep on the 24-hour cortisol secretory profile. Sleep 199518 549-556.

25 Weibel L \& Brandenberger G. Disturbances in hormonal profiles of night workers during their usual sleep and work times. Journal of Biological Rhythms 199813 202-208. (doi:10.1177/ 074873098129000048)

26 Spiegel K, Leproult R, L'Hermite-Baleriaux M, Copinschi G, Penev PD \& Van Cauter E. Leptin levels are dependent on sleep duration: relationships with sympathovagal balance, carbohydrate regulation, cortisol, and thyrotropin. Journal of Clinical Endocrinology and Metabolism 200489 5762-5771. (doi:10. 1210/jc.2004-1003)

27 Vgontzas AN, Bixler EO, Lin HM, Prolo P, Mastorakos G, Vela-Bueno A, Kales A \& Chrousos GP. Chronic insomnia is associated with nyctohemeral activation of the hypothalamicpituitary-adrenal axis: clinical implications. Journal of Clinical Endocrinology and Metabolism 200186 3787-3794. (doi:10. 1210/jc.86.8.3787)

28 Deuschle M, Schweiger U, Weber B, Gotthardt U, Korner A, Schmider J, Standhardt H, Lammers $\mathrm{CH} \&$ Heuser I. Diurnal activity and pulsatility of the hypothalamus-pituitary-adrenal system in male depressed patients and healthy controls. Journal of Clinical Endocrinology and Metabolism 199782 234-238. (doi:10. $1210 /$ jc.82.1.234)

29 Brismar K \& Hall K. Clinical applications of IGFBP-1 and its regulation. Growth Regulation 19933 98-100.

30 Katz LE, Jawad AF, Ganesh J, Abraham M, Murphy K \& Lipman TH. Fasting C-peptide and insulin-like growth factorbinding protein-1 levels help to distinguish childhood type 1 and type 2 diabetes at diagnosis. Pediatric Diabetes 20078 53-59. (doi:10.1111/j.1399-5448.2007.00236.x)

Received 3 June 2010

Accepted 28 June 2010 